\title{
Perspectives of husbands of women with breast cancer: Information needs
}

\author{
By Margaret I. Fitch and Marc Allard
}

\section{Abstract}

The majority of women, when diagnosed with breast cancer, turn to their partners for support. However, the diagnosis and treatment of this disease will have an impact on the partner as well and could influence his ability to be supportive. This study was undertaken to explore the perceived informational needs of male partners of women diagnosed with breast cancer. The in-depth interviews provide a rich description about the nature of men's informational needs in a context of upheaval and unexpected events. The 15 husbands in this study described information as important in their capacity to manage the situation. Three overarching themes were identified: the men had questions and concerns throughout the time period since the diagnosis, lack of information created difficulties for them, and health care professionals could be helpful. These men struggled to find relevant information and to sort out what was applicable to their own situation. They found little information specifically directed to partners. Assessment by cancer nurses ought to include the male partner's needs for information and his capacity to process information throughout the cancer experience.

\section{Introduction}

In Canada, 21,600 women are diagnosed with breast cancer annually and 5,300 die of the disease (NCIC, 2005). The impact of this disease and its treatment is more than just physical. Women have reported there are emotional, social, psychological, financial and practical consequences as well (Carlsson \& Hamrin, 1994; Hilton, 1996; Rendle, 1997). These women have cited access to information as key to coping and dealing with the experience (Gray, et al., 1998; Rees \& Bath, 2000) and many initiatives have been undertaken to meet their information needs over the past decade (Ontario Breast Cancer Information Exchange Partnership - OBCIEP).

The majority of women are married or living with a partner at the time of the breast cancer diagnosis. Often, they turn to their partner as a primary source of support (Bultz, Speca, Brasher, Geggie, \& Page, 2000). However, the disease and its treatment will have an impact on the partner as well, and the consequences may have an influence on his capacity to be supportive. To date, little attention has been paid to the male partners' perspectives about their own need for information in order to cope and be supportive in this situation.

This study was undertaken to explore the information needs of husbands of women who have been diagnosed with breast cancer. Indepth interviews provided a rich sense of the type of questions men have when their wives are living with breast cancer. The insight provided by the men offers a foundation to design interventions or approaches to individuals in the same situation.

\section{Background}

During the past 15 years, there has been a substantial increase in the amount of quantitative information about the impact of a woman's diagnosis of breast cancer on a partner (husband) and family. There is

\section{Dr. Margaret Fitch, Toronto Sunnybrook Regional Cancer Centre, Toronto, $O N$.}

Marc Allard was a second-year medical student at the time of the study and is continuing his studies at the University of Toronto.

E-mail: marg.fitch@sunnybrook.ca an unequivocal recognition that cancer is a family experience (Yates, 1999). The body of knowledge supporting this view has grown over these years in four phases (Lewis, 2004). The first and early work focused on the impact of psychosocial morbidity in the women and its ramification for the partners. This early phase served to raise awareness about the desirability of including the partner in conversations about treatment and in decision-making (Ervin, 1973; Kent, 1975; Wellisch, Jamieson, \& Pasnau, 1978; McGuire, 1981). The second phase of research measured psychosocial distress in both women diagnosed with the disease and in the partners (Oberst \& James, 1985; Northouse \& Swain, 1987; Northouse, 1988). The partner's distress was recognized at this point in time as being as high, if not higher, than the women's (McGuire, 1981; Baider \& De-Nour, 1984). Subsequently, phase three saw statistical modelling techniques applied to test hypotheses about breast cancer impact on the family (Lewis, Woods, Hough, \& Bensley, 1989; Lewis, Hammond, \& Woods, 1993; Woods \& Lewis, 1995; Lewis \& Hammond, 1996). These empirical studies led to the latest phase or the development of the Relationship Model of Family Function with Cancer (Lewis, et al., 1993) as a framework for oncology nursing practice. The model is based on cancer as a psychosocial transition in which family members work to find a balance in their ongoing life as a family. When illness strikes a patient, the family is required to maintain stability in its routine internal arrangements and activities as well as restructure its interactions and activities to manage the ongoing demands of the illness (Yates, 1999).

Access to information is a key factor to achieve a sense of balance in managing the illness. Quantitative reports regarding the informational needs of male spouses when a wife is diagnosed with breast cancer have highlighted the importance men assign to various topic areas (Nikoletti, Kristjanson, Tataryn, McPhee, \& Burt, 2003), described information flow between partners (Rees \& Bath, 2000), and identified the areas of unmet information needs (Kilpatrick, Kristjanson, Tataryn, \& Fraser, 1998). Unmet information needs have been correlated with higher psychosocial distress (Bultz, et al., 2000; Baider et al., 2004). Qualitative work described the experience of having a diagnosis of breast cancer and emphasized that having access to information is an important consideration (Samms, 1999; Hilton, Crawford, \& Tarko, 2000). However, it remains unclear what the nature of the information needs is and if there are unique aspects to providing information for male partners of women diagnosed with the disease. It is also unclear how the needs for information may change over time. Much of the existing research focuses on the time surrounding initial diagnosis and not at a later point along the trajectory of the illness. Qualitative inquiry was needed as an initial step in exploring these areas.

\section{Purpose}

This study was undertaken to explore the perceived information needs of male partners of women diagnosed with breast cancer. An increased understanding about their needs for information content and provision would help to determine if specific interventions are needed for men facing this life event. Much information has been developed for women and it was unclear if male partners required different or unique interventions.

\section{Methods}

This descriptive qualitative study made use of in-depth interviews to explore men's needs for information during the experience of having a wife diagnosed and treated for breast cancer. The open- 
ended interview questions allowed the participants to discuss the events surrounding the breast cancer diagnosis and treatment, their responses to those events, the information they wanted or sought, and how they managed with the changes. If the participant did not mention the topics on his own, specific probes were used to ask about changes at work, in daily life, and with relationships.

Men were accrued by sending invitations to member support groups of the Ontario Breast Cancer Information Exchange Partnership (OBCIEP). The member agencies distributed the invitations to their members, women living with breast cancer, who shared the invitation with their partners. Interested individuals contacted the OBCIEP office and the research assistant explained the participation requirements in detail. To be eligible, the men had to be a partner of a woman diagnosed with breast cancer, preferably within the past two years, and be able to speak English. However, all men who came forward and volunteered were included.

Consenting participants were interviewed over the telephone and the sessions were audiotaped. Consent forms were sent to participants for signatures prior to the interview, together with a copy of the interview guide. The interviewer was a male medical student (research assistant) prepared to conduct the interviews. The interviews lasted between 30 and 60 minutes. The interviews were open-ended and began by asking participants about the events surrounding the diagnosis and treatment of their partner's breast cancer. Subsequently, they were asked to describe the concerns and questions they had, their search for information, and how they thought health care professionals could improve the situation.

\section{Analysis}

The interview audiotapes were transcribed verbatim and subjected to a content analysis (Silverman, 2000). The analysis was conducted with a view to understanding and describing the needs these male partners had for information and their experiences searching for information. The investigators read each of the interviews separately and made marginal notes about the free range of content in each interview. The investigators subsequently compared their notations about the content and agreed upon the coding categorization. One investigator then completed the coding of the content for all interviews (MF). Each coded category was reviewed and the content within each was summarized. Review across all categories was then undertaken to identify the key ideas (themes) that would reflect across the content categories. The two overarching key ideas are used to frame the description of the findings below.

\section{Findings}

\section{Selected characteristics}

Fifteen men participated in this study. Three lived in Toronto, three in Peterborough, and nine in Ottawa. Selected demographic information is presented in Table One about the men and their female partners. All were living with their wives at the time of the interviews.

\section{Theme: Information needs were evident \\ throughout the experience of breast cancer}

Throughout the course of their experience with breast cancer, the men in this study experienced worries and had questions. Their interviews revealed a long list of topics for which they wanted information and for which many felt they did not have clear answers, not only at the time of the diagnosis, but also during and after treatments.

At the time of their wife's initial cancer diagnosis, not knowing about the disease, the treatment options or the anticipated outcomes was disturbing for these men.

You know, cancer is a scary word. I really did not know much about it in the beginning... it really is the worst thing I've ever gone through... when so much is unknown, I mean they can't really give you answers most of the time, and that is scary... you really don't know what you're dealing with... I did not know about prognosis, what it meant... the whole thing was like a bad dream. (2)

Without a lot of knowledge about breast cancer and the treatment options, most men initially thought they would lose their wife. They equated cancer with death. The diagnosis was not something they had been thinking about and it came into their lives unexpectedly. Many described a sense of being unprepared and not having information at the beginning of the experience.

It was a shock. Definitely a shock. It was not something I was expecting at all. I really didn't know anything about it, about breast cancer, and the first thing that went through my mind was that she wouldn't make it, that she'd die. (5)

The whole thing was a shock. I was shocked... really caught off guard. I didn't really know about the disease or the different treatment options. Nothing. (1)

As they learned more about the disease and potential outcomes, the initial fear these men experienced lessened. The learning came from living through the actual events and accessing information from various sources.

It's not as scary as it was before, at the beginning. Now that we've gone through all the treatment and learned a whole lot about it, breast cancer... it's not as scary as it was before. (2)

For a while you get quite depressed. Then, the more you read, the more you understand and the better you feel. (5)

Their access to information about breast cancer and their knowledge about prognosis helped initially, but actually heightened their fear at the time of recurrence. If there was a second diagnosis, their previous experience with treatment and their understanding about recurrence reinforced and heightened the fears about losing their wives.

The biggest thing is the worry about recurrence. The thinking about recurrence is tough... each mammogram is an anxious time... The only outcome I ever considered is that she would be okay, that she would survive. I was so naive. If I knew then what I know now I think my emotional state would have been a lot worse than it was. (1)

A wide range of information was seen as desirable by these participants. Topic areas that the men cited as important for them included, first and foremost, information about the disease, its treatment options, and prognosis. Specifically, they struggled with why the disease was diagnosed in their wife, why it happens in young women, why it is diagnosed seemingly by chance, and why chemotherapy is recommended when it is so hard to take and relatively ineffective. Sometimes the information desired was quite specific.

\begin{tabular}{|l|l|l|}
\hline \multicolumn{3}{|l|}{ Table One. Selected demographic characteristics $(\mathbf{N}=\mathbf{1 5})$} \\
\hline Age in years (participants) & $\begin{array}{l}\text { average (SD) } \\
\text { range }\end{array}$ & $\begin{array}{l}53( \pm 11.89) \\
34-71\end{array}$ \\
\hline Age in years (wives) & $\begin{array}{l}\text { average (SD) } \\
\text { range }\end{array}$ & $\begin{array}{l}47( \pm 10.37) \\
33-64\end{array}$ \\
\hline Years married & $\begin{array}{l}\text { average (SD) } \\
\text { range }\end{array}$ & $\begin{array}{l}25( \pm 12.56) \\
7-45\end{array}$ \\
\hline Number with children & $<10$ years & 5 \\
& $>10$ years & 11 \\
\hline Number retired (participants) & & 3 \\
\hline Time since diagnosis (wives) & average (yrs) & 3.06 \\
range & $0.5-19$ \\
\hline
\end{tabular}


When we found out for certain it was cancer, I wanted so much information. I wanted to know so much, like what size it was, what grade it was, you know... I really would have liked the information directed to me, too. I would like to have been more involved in the decision and what is going to happen, especially after surgery... There was really nothing before the operation, the lumpectomy. I thought it would be better to tell me ahead of time what to expect, like how to cope, what to do, before and after the treatment. (2)

At each stage of the experience, there were new questions about procedures, test results, and side effects. Questions about nutrition, lifestyle changes and herbal remedies were mentioned frequently as the ones that arose particularly after the initial rounds of treatment were finished. But these were often topics men found were not easy to find out about.

We had a lot of questions about what to do once the treatment finished. I mean, we wanted to make sure we did everything we could do to make sure it didn't come back, but we had trouble knowing what to do... what about eating, exercising, meditating, isn't it all supposed to help? (7)

\section{Theme: The lack of clear answers created difficulties for the men}

When the men in this study did not have relevant information or answers to their questions, they felt distressed and frustrated. The lack of clarity in information created levels of psychosocial distress for these men, described in terms of worries, uncertainty and frustrations. They described frustration with the level of uncertainty regarding disease progression and treatment outcomes, as well as the apparent inability of health care practitioners to be clear about what lies ahead for the couple. They were surprised by the differences in opinion they read in the various information documents or heard from various physicians and surgeons. They thought having a clear answer about the pathway ahead for them would have been preferable to the experience they had undergone.

It's particularly difficult not to have a definite answer. I'd be much happier if I'd been given a definite answer. I needed a good idea about what was going on and what was going to happen. Everything is so up in the air. No one could just give me a good sense of what will happen with the disease, like it is all so unsure. (10)

When I think back to that time, I really felt quite helpless. Really. I did not know how to deal with her or how to treat her... I had so many questions, about what was happening, what was going to happen, and how I could support her. It was quite a powerless feeling overall. (3)

Finding information and beginning to understand what might happen was a help to the men in this study. They described using a wide range of information sources beyond the doctors and nurses at the cancer centres: books, internet, videos, libraries, peer groups. However, in their search, they struggled with the information presented in statistical terms, the medical language, separating out the facts that applied to their own wife, coping with the vast amount of information, and coming to terms with how much disagreement existed among professionals. Many experienced a sense of overload with all the information they found, especially if they could not sort out what applied to their own situation.

We really went looking for information, and did it together over the Internet. It was like turning a light on in the room. It makes it all less scary. (14)

I found it frustrating that you couldn't seem to get a straight answer, get one answer from the doctors. Everyone has a different opinion when you start reading. And I found it quite hard to sort through all of it and make real sense of it. Like, what really applied to us? What was relevant? (5)
For the most part, these men did not go seeking much information on their own. Many relied on the information their wives brought home, or the conversations they had personally with the health care professionals. Their wives brought information home from support group meetings or from chat line discussions. Some worked together with their wives to find information on the internet or talked with other patients or partners while at the cancer clinic. Overall, they thought they had access to a great deal of information. Nonetheless, all identified specific topics for which they could not find relevant information. In particular, none of these men felt there was information directed specifically for partners to help them cope or manage with the situation.

I was surprised that I wasn't given information myself. I would have liked to have had information directed to me... I read everything my wife brought home and it was good, but like... basically the information was for the woman, not the husband. The doctor concentrated solely on my wife and didn't really consider me at all. (2)

It seems like a lot of information is for the woman and about the treatment. There's not a lot, not too much for husbands. Not much at all, especially about how to cope. There's not much for husbands. (12)

The men were continuing to struggle with unanswered questions and worries at the time of the study interview, more than two years after the initial diagnosis. They had concerns about the future, in general, and their wife's health (well-being) specifically. In particular, men worried about recurrence no matter where their wife was in her cancer journey. It was an ever-present spectre in their lives and was brought to the forefront with every mammogram or with any unexpected pain or discomfort. These men described not knowing what to be concerned about or what could be ignored. As a result of the lack of clarity, they felt they were living with a high degree of uncertainty.

I am worried about recurrence. What if it comes back? What new issues will arise then? How will she deal with it? How will I deal with it? (9)

You know, every ache or pain you worry about. You wonder what's happening. You wonder if the cancer has gone to other parts of her body. It's almost as stressful after treatment now as it was during treatment. It's hard not knowing what the outcome is going to be. (12)

The men whose wives had had recurrent disease talked about facing certain loss of their partner through death. They, too, described the challenges of living with uncertainty and unanswered questions on a daily basis.

It's been difficult facing the fact my wife will die. And die soon. I try to keep positive, but it's hard. (4)

I find it's always on my mind. I'm always thinking about it, and feeling sad. I know it will happen, but exactly when? And how? What will she be like? How will I handle it all? (11)

The men in this study used various strategies to cope with the impact of their partner's breast cancer and its aftermath. They talked about receiving support from family members, friends, co-workers, other patients, and their partners, in addition to health care professionals. For information, they turned to friends and other cancer patients. For understanding, they turned to their partners. Co-workers helped re-arrange their working lives. Issues arose when family members were not able to pitch in and help or when friends did not visit or want to talk about the cancer. The men felt uninformed about available services. Many men found the only people who really understood what was happening for them, and were ready to talk about it all, were others who had gone through the same experience.

Sometimes I think that the only people who can really offer support and good advice are those people who have gone through the same experiences... we find a closeness to another family going through the same thing. (13) 
The men looked to their wives and children for support or tried to draw from within themselves. They talked about keeping a positive attitude, rolling with the punches, getting through one thing at a time, managing one day at a time, keeping to a routine, taking stock of priorities, getting information, and looking after one's own health as ways they found to cope with the situation. Without exception, getting information was seen as helpful.

Overall, these men found there was little to support or help husbands specifically. They perceived much of the attention was on the woman, almost to the exclusion of the husband. They reported no one had given them written information directed specifically toward husbands or told them about any support groups. Often, they felt they had to be self-reliant and manage on their own. Few found any formally organized programs for husbands.

We use each other for support. We could ask the family, but we are pretty private and don't ask... I talk to people at work and they are great. They give me a lot of encouragement and support... but, you know, I am the type of guy who likes to do things for himself, you know, take care of things myself. (11)

I think there is very little support for the husband... it seems like the attitude is like, 'this is a woman's issue and this is about me and my body and no one else is going to be involved'. (10)

My support, well, I guess it comes from inside. There really is no support for husbands. We have our own feelings and thoughts, and wonder if we are doing the best... It might be good to talk with other husbands in the same situation, just sit and compare notes one to one. (5)

\section{Theme: Health care professionals can be more helpful}

Most of the participants had comments about how health care professionals could be more helpful to the partners of women diagnosed with breast cancer. They emphasized more than any other idea, the need to acknowledge and include the partner. They thought there needed to be more openness on the part of health care professionals to having partners present and involved in the decisions and discussions. This type of inclusion would help with information exchange. As a partner, knowing what their wife knows was seen as useful.

You have to remember that the partner is hurting, too. He's hurting pretty badly, too... they ought to check with the husbands, ask how they are doing, how they are coping... we go through a lot but nobody seems to notice. (2)

The family, the husband, they take backstage during the treatment... it would be nice to have a little more attention. It's hard for us, too. It all has an effect on us, too. And it would be nice if that was acknowledged. (5)

Including the husbands in conversations, talking with the husband, and involving the husband in appointments and in decision-making discussions were cited as important strategies for cancer care professionals to use. Based on these interviews, there is still variation in how often this happens in clinical situations.

I think it would be useful to have husbands included in the visit with the doctor. If this is really supposed to be a partnership, this would make sense. You hear different things than your wife hears. (3)

I have tried to go to all my wife's appointments with her. But, you know, the surgeon did not even talk with me. Just to her. He did not ask me any questions. Basically he ignored me. (10)

It was great. The doctor and nurses acknowledged me and gave me the full treatment, like I was part of it all. I had the information I needed and they kept me informed and. I guess you could say I got the help I needed. (14)

The men in this study emphasized the idea that health care professionals need to show compassion. This happens through the communication exchange, the invitations to participate in discussions, the information that is provided, the response to questions, and openness or honesty with which health care professionals interact. Understanding what the partner is experiencing and acknowledging the reality of that experience are part of showing compassion.

I think the best way to help is just show more compassion. It's tough to go through this and it's hard to know what to do. They could understand that, show they understand that, more. (1)

The communication approach these men thought would be helpful was described as "...clear and straight-forward" (9), "...to the point and almost be blunt" (6), and "...upfront and honest" (4). If there was no clear answer, or if a health care professional did not have an answer, then that ought to be stated. The men wanted to know exactly what they were facing and what resources were available to help them deal with the situation.

I think some of the things that would really help would be, a 1-800 number you could call and ask questions and get the information you need. And a standard package, you know, one that everyone gets with all the basic information, and how husbands are supposed to cope, that would be good. (2)

Access to information was cited repeatedly by the men as important and beneficial to them. For example,

I guess I managed by getting information, you know, to understand what was going on... I talked with people. I remained positive. I tried to make certain I did not get down... I read a lot of books about the emotional side of cancer and dealing with the disease and even though it was hard to read it, it was good for me. (3)

A key point reiterated by these men was the struggle to make sense of all the available information, to sort through the controversies, and determine what actually applied in the case of their wife. Being able to have a direct and focused conversation with an oncologist or a nurse was described as very useful.

We got numbers at the hospital of where we could call, but we had to make the calls ourselves. We had to see it all out... I went to the hospice and the cancer centre library and there was lots of information. But, you know, after awhile it's overkill. There's so much. Too many options, too many concerns to read and sort out. (3)

There's a lot of information out there and we try to keep up with it all. Whenever we are not sure about something or have a question or can't find what we're looking for, we can talk to Dr. A. or the nurse at the clinic. They are always so helpful. They answer the question and sort us out. (6)

The men in this study thought health care providers ought to be giving them clear information. They wanted clarity around the disease, how the treatment would work, and the prognosis. Many were very disturbed about the degree or amount of disagreement amongst professionals about treatment and want them to provide more definitive answers to questions and recommendations for what needed to be done for their wives.

I really did not know about all the different types of cancer and all the treatments... everyone pushing something different... even alternative therapies... I really get frustrated trying to sort it all out. (13)

We get different vibes from different doctors. One says one thing and the next says something different. Why can't they just be clear and have a standard treatment? (12)

It was difficult to handle all the unknown around the disease and not knowing what to expect. What would the outcome be? What can you expect? What do the percentages really mean? I would have preferred just knowing the answer, knowing the outcome. (6)

Everything is in percentages and probabilities. There's no definitive answer. (15) 
I found it surprising that the doctors all disagree so much. They keep saying they are a team, but they have different ideas about what is needed. (14)

The other recommendation these men offered to health care providers concerned the detail in information health care professionals provided and the directions to patients and partners about where to search for information. The men wanted detail and they thought clear instructions about where to search for information would be valuable. They thought specific directions about where to go for certain information or what to look for would have been useful. There was a clear sense that health care professionals could have saved them energy and reduced frustration by providing clear directions.

I thought there could have been more detail. There wasn't enough detail in the material we were given. More information was needed about different treatment options, radiation doses, and radiation treatment. (15)

I sorted through a ton of information. Everything I could get my hands on. An enormous amount. But it took us a while to find it all. A couple of months to get our hands on anything useful. No one told us where to go to find it. (13)

Finally, the specific recommendations these men made regarding available resources included:

I really think doctors and nurses need to tell patients about what is available, you know, the services and the help, what is available and how to get it. (11)

Nobody told us about the support services and what is available. (8)

Someone said something about support groups, but no one came right out and told me about a group I could go to. (10)

It would have been good to have been directed to a few good books just to get started with, get started down the right path. (14)

\section{Discussion}

The findings of this study add to a growing body of knowledge and understanding about the information needs husbands experience when their wives are diagnosed with breast cancer. Although we used the terminology of male partner, all who came forward were husbands. When cancer is diagnosed, it is not only the person with the disease that must face challenges and uncertainties. Partners are clearly influenced as well.

The men in this study had many questions throughout the illness experience. To a greater or lesser extent, they had had access to information and found answers to many of their questions, although the search was frustrating. It is important to note that the men in this study were self-selected and took the initiative to contact the OBCIEP office. They were accrued through the breast cancer support group network. In this regard, they may not be truly reflective of all men whose wives are diagnosed with breast cancer.

The nature of the questions identified by the men was very similar to those identified by women diagnosed with breast cancer in other studies (Gray et al., 1998; Rees \& Bath, 2000). Questions about the disease, treatment options, and prognosis are consistently cited as important topics, especially at the time of diagnosis. Questions about how to cope with the long-term side effects and how to access community resources arise somewhat later in the illness experience. Clearly issues and concerns changed over time for these men.

That partners experienced difficulties getting all the information they wanted also reflects what breast cancer patients have identified. Although basic information may be available, specific information related to a particular situation can be more difficult to find (Fitch, Nicoll, \& Keller-Olaman, 2005). Women have also identified the issues of information overload, trying to sort through and make sense of the information they find, and trying to identify what is relevant to them. Many of the suggestions these men made about how improvements could be made have also been made by breast cancer patients (Trussler, 2001).

The men in this work identified a clear gap in the provision of information regarding breast cancer in terms of very explicit information directed to, and for partners. They would like health care professionals to be more inclusive of them as partners during office visits and clinic appointments. They also wanted written information to be available about how they can cope with the situation as partners. Much of the current information they felt had been written for women. They would like to see brochures and booklets directed to husbands about coping with the issues they are facing. Although many mentioned support groups, none actually had experience with groups designed specifically for partners. They were not aware of any that existed.

\section{Implications for practice}

The findings of this work have several implications for cancer nurses who care for women with breast cancer. The impact of the diagnosis and its treatment will have an impact on the partner as well as the woman. As a nurse, it is important to recognize and acknowledge this dual impact. The partner is likely going to be struggling with changes and uncertainties in the same fashion as the woman. If he is to be supportive to the woman, attention must be given to his emotional state and to his information needs. The nursing assessment ought to include the partner as well as the patient and focus on the partner's personal reactions and concerns to the situation. This assessment may need to be made during a one-on-one conversation with the partner where questions can be posed about his worries, concerns, and desire for assistance. Different individuals will have different concerns or questions.

A discussion ought to be held regarding how best to include the partner in office or clinic appointments and in the decision-making process. This discussion ought to be held with the partner and the patient early in the cancer episode. Partners may need clearly stated instructions about how they can participate in clinic or hospital settings and information to enable them to participate effectively. The nurse has a responsibility to determine both the patient and partner preferences for participation and subsequently work to achieve the preferred level of engagement. This may require advocating with other members of the health care team.

Based on these study findings, there is a clear implication for nurses around clarifying medical language and interpretation; helping partners sort through the information they are reading; helping them to identify what is relevant to their situation and clarifying misconceptions; and being available for (and responding to) questions. It would be prudent to offer these options to patients and partners early in the cancer experience and to check in with them on a regular basis during the course of treatment. Nurses could also play a key role in referring partners to information sources. It could be useful to prepare a handout listing key information resources in the community and give that handout to partners.

Finally, there is indication from this work that a written information resource could be beneficial to male partners of women diagnosed with breast cancer. This resource ought to include information specifically for the partners and describe how they might manage with the specific issues they face. 
References

Baider, L, Andritsch, E., Goldzweig, G., Uziely, B, Ever-Hadani, P., Hofman, G., Krenn, G., \& Samonigg, H. (2004). Changes in psychosocial distress of women with breast cancer in long term remission and their husbands. Psychosomatics, 45(1), 58-68.

Baider, L., \& De-Nour, A.K. (1984). Couples' reactions and adjustment to mastectomy: A preliminary report. Journal of Psychiatry in Medicine, 14, 265-76.

Bultz, B.D., Speca, M., Brasher, P.M., Geggie, P.H., \& Page, S.A. (2000). A randomized controlled trial of a brief psychoeducational support group for partners of early stage breast cancer patients. Psycho-oncology, 9(4), 303-13.

Carlsson, M., \& Hamrin, E. (1994). Psychological and psychosocial aspects of breast cancer and breast cancer treatment: A literature review. Cancer Nursing, 17, 418-28.

Ervin, J. (1973). Psychological adjustment to mastectomy. Medical Aspects of Human Sex, 7, 42-65.

Fitch, M.I., Nicoll, I., \& Keller-Olaman, S. (2005). Breast cancer information dissemination: Finding out what works. Supportive Care in Cancer, 13(6), 22-167 (p. 469).

Gray, R.E., Fitch, M., Greenberg, M., Hampson, A. Doherty, M., \& Lebrecque, M. (1998). The information needs of well, longer-term survivors of breast cancer. Patient Education and Counselling, 33, 245-255.

Hilton, B.A. (1996). Getting back to normal: The family experience during early stage breast cancer. Oncology Nursing Forum, 23, 605-14.

Hilton, B.A., Crawford, J.A., \& Tarko, M.A. (2000). Men's perspectives on individual and family coping with their wives' breast cancer and chemotherapy. Western Journal of Nursing Research, 22(4), 438-59.

Kent, S. (1975). Coping with sexual identity crises after mastectomy. Geriatrics, 30, 145-6.

Kilpatrick, M.G., Kristjanson, L.J., Tataryn, D.J., \& Fraser, V.A. (1998). Information needs of husbands of women with breast cancer. Oncology Nursing Forum, 25(9), 1595-601.

Lewis, F. (2004, August). The impact of cancer on the family. Robert Tiffany Lectureship. 13th International Conference on Cancer Nursing. Sydney, Australia.

Lewis, F.M., \& Hammond, M.A. (1996). The father's, mother's and adolescent's adjustment to a mother's breast cancer. Family Relations, 45, 456-65.

Lewis, F.M., Hammond, M.A., \& Woods, N.F. (1993). The family's functioning with newly diagnosed breast cancer in the mother: The development of an exploratory model. Journal of Behavioral Medicine, 16, 351-370.

Lewis, F.M., Woods, N.F., Hough, E.E., \& Bensley, L.S. (1989). The family's functioning with chronic illness in the mother: The spouse's perspective. Social Science Medicine, 29, 1261-69.
McGuire, P. (1981). The repercussions of mastectomy on the family. International Journal of Family Psychiatry, 1, 485503.

National Cancer Institute of Canada. (2005). Canadian Cancer Statistics 2005. Toronto: Author.

Nikoletti, S., Kristjanson, L.J., Tataryn, D., McPhee, I., \& Burt, L. (2003). Information needs and coping styles of primary family caregivers of women following breast cancer surgery. Oncology Nursing Forum, 30(6), 987-96.

Northouse, L. (1988). Social support in patients' and husbands' adjustment to breast cancer. Nursing Research, 37, 91-5.

Northouse, L., \& Swain, M.A. (1987). Adjustment of patients and husbands to the initial impact of breast cancer. Nursing Research, 36, 221-5.

Oberst, M.T., \& James, R.H. (1985). Going home: Patient and spouse adjustment following cancer surgery. Topics in Clinical Nursing, 7, 41-57.

Ontario Breast Cancer Information Exchange Partnership. www.obciep.on.ca

Rees, C.E., \& Bath, P.A. (2000). Exploring the information flow: Partners of women with breast cancer, patients, and health care professionals. Oncology Nursing Forum, 27(8), 1267-75.

Rees, C.E., \& Bath, P.A. (2000). The information needs and source preferences of women with breast cancer and their family members: A review of the literature published between 1988 and 1998. Journal of Advanced Nursing, 31, 833-41.

Rendle, K. (1997). Survivorship and breast cancer: The psychosocial issues. J Clin Nursing, 6, 403.

Samms, M.C. (1999). The husband's untold account of his wife's breast cancer: A chronologic analysis. Oncology Nursing Forum, 26(8), 1351-8.

Silverman, D. (2000). Doing qualitative research: A practical guide. London: Sage.

Trussler, T. (2001). Uncovering the gaps: The journey to supportive care. Vancouver: Canadian Breast Cancer Foundation/BC and Yukon Division.

Wellisch, D.K., Jamieson, K.R., \& Pasnau, R.O. (1978). Psychosocial aspects of mastectomy II: The man's perspective. American Journal Psychiatry, 135, 543-546.

Woods, N.F., \& Lewis, F.M. (1995). Living with chronic illness: Women's perspectives on their families' adaptation. Health Care Women International, 16, 135-48.

Yates, P. (1999). Family coping: Issues and challenges for cancer nursing. Cancer Nursing, 22(1), 63-71. 